\title{
Ön çapraz bağ cerrahisi revizyonları
}

\section{Revisions of anterior cruciate ligament reconstruction}

\author{
Mehmet Aşık, Taha Kızılkurt, Gökhan Polat
}

İstanbul Üniversitesi İstanbul Tıp Fakültesi, Ortopedi ve Travmatoloji Anabilim Dalı, İstanbul

Ön çapraz bağ (ÖÇB) rekonstrüksiyonu sayısı arttı̆̆ı gibi revizyon ÖÇB gereksinimi de artmaktadır. Başarısız bir ön çapraz bağ rekonstrüksiyonunun revizyonu karmaşık bir prosedürdür. Primer ÖÇB rekonstrüksiyonu tedavisinin başarısız olmasında hasta yaşı, teknik hatalar, travma, enfeksiyon, spontan biyolojik yetmezlik gibi birçok risk faktörü mevcuttur. ÖÇB rekonstrüksiyonu sonrası en sık görülen tekrarlayan instabilite nedeni cerrahi teknik hatalardır. Tünel yerleşiminin uygun olmaması ise en sık teknik hata nedenidir. Primer ÖÇB rekonstrüksiyonunun başarısızlık nedenleri çok iyi anlaşılmalı ve buna uygun cerrahi planlama yapılmalıdır. Bu amaçla iyi bir hikâye alımı ve fizik muayene sonrasında standart anterior-posterior (AP), lateral ve tünel grafileri, alt ekstremite ortoröntgenografi, manyetik rezonans ve bilgisayarlı tomografi ile değerlendirilmelidir. Ek menisküs yaralanmaları, kemik tüneller, kıkırdak yaralanmaları, kemik deformite, enfeksiyon varlığı, greft seçenekleri ve hasta aktivite düzeyine göre de uygun cerrahi teknik seçilmelidir. Literatürde revizyon ÖçB cerrahisinde, primer ÖÇB rekonstrüksiyonu kadar tatmin edici sonuçlar alınamadığı söylense de iyi bir planlama ve uygun teknik ile tatmin edici sonuçlara ulaşılabilmektedir.

Anahtar sözcülkler: ön çapraz bağ rekonstrüksiyonu revizyonu; teknik hatalar; tünel malpozisyonu
As incidence of anterior cruciate ligament $(A C L)$ reconstruction increases, the rate of revision surgery also increases. Revision of a failed anterior cruciate ligament reconstruction is a complex procedure. There are many risk factors such as patient age, technical errors, trauma, infection, spontaneous biological failure in the failure of primary ACL reconstruction treatment. The most common cause of recurrent instability after ACL reconstruction is surgical technical errors. Inadequate tunnel placement is the most common cause of technical error. The causes of the primary $\mathrm{ACL}$ reconstruction failure should be determined, and careful surgical planning should be done accordingly. For this purpose, after taking a good history and physical examination, standard anterior-posterior (AP), lateral, tunnel radiographs, lower extremity orthoroentgenogram, magnetic resonance and tomography should be evaluated. Appropriate surgical technique should be chosen according to additional meniscus injuries, bone tunnels, cartilage injuries, bone deformity, presence of infection, graft options and patient activity level. Although revision ACL reconstruction has been documented to have worse outcomes compared with primary $\mathrm{ACL}$ reconstructions, satisfactory results can be achieved with good planning and appropriate technique.

Key words: revision anterior cruciate ligament reconstruction; technical errors; tunnel malposition

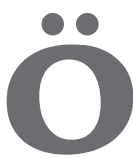

n çapraz bağ (ÖÇB) yaralanması sıklıkla spor kaynaklı olmakla birlikte düşük olasılıkla günlük aktiviteler veya yüksek enerjili travma ile de oluşabilir. ${ }^{[1]}$ Türkiye'de ÖÇB yaralanma insidansı bilinmemekle beraber, başka kaynaklarda 32-52/100.000 aralığında bildirilmiştir. ${ }^{[2,3]}$ ABD'de yıllık ÖÇB rekonstrüksiyonu ameliyatı 100.000 ile 150.000 arasında olduğu bildirilmiştir. ${ }^{[4]}$

Yılık ÖÇB rekonstrüksiyonu ameliyat sayısının artması sonucunda başarısızlıkla sonuçlanan cerrahi girişimlerin ve yeniden oluşan yırtıkların sayısı da artmaktadır. Dolayısıyla ÖÇB revizyon ameliyatı sayısı da artmaktadır. ÖÇB rekonstrüksiyonu ameliyatı etkili bir ameliyat olmasına rağmen, başarı oranı hâlâ \%75-97 arasındadır. ${ }^{[5]}$ Literatürde yıllık ÖÇB rekonstrüksiyonu sonrası yeniden rüptür insidansı \%4,3-23,3 arasında değişmektedir. ${ }^{[6]}$ Primer ÖÇB rekonstrüksiyonun başarısını etkileyen birçok faktör bulunmaktadır. Bunların arasında ameliyat öncesi dizdeki laksite, ikincil stabilize edici yapıların durumu, menisküs ve kıkırdak yapılardaki yaralanma, kullanılan greft, cerrahi teknik, ameliyat sonrası rehabilitasyon, hastanın motivasyonu ve beklentileri sayılabilir.

- Illetişim adresi: Op. Dr. Taha Kızılkurt, İstanbul Üniversitesi İstanbul Tıp Fakültesi, Ortopedi ve Travmatoloji Anabilim Dalı, İstanbul Tel: 0506 - 5026187 e-posta: drtahakizilkurt@gmail.com

- Geliș tarihi: 24 Mart $2020 \quad$ Kabul tarihi: 4 Mayıs 2020 
Johnson ve $\mathrm{Fu}$, ÖÇB rekonstrüksiyonu sonucu tekrarlayan instabilitesi bulunan veya stabil ama ağrılı ve hareket kısıtlılı̆ ${ }^{\prime}\left(10^{\circ}-120^{\circ}\right.$ arası $)$ olan dizleri başarısız olarak tanımlamışlardır. ${ }^{[7]}$ ÖÇB rekonstrüksiyonu başarısızlık nedeni genellikle multifaktöriyeldir. ÖÇB revizyon cerrahisinde sonuçlar primer ÖÇB rekonstrüksiyon cerrahisi kadar yüz güldürücü olmasa da ÖÇB revizyon cerrahisiyle diz stabilitesi ve hasta tatmini sağlanabilmektedir. ${ }^{[8]}$

\section{ÖÇB REKONSTRÜKSIYONU BAŞARISIZLIK NEDENLERI}

Primer ameliyat başarısızlık nedenleri tabloda gösterildiği gibi sıralanabilir (Tablo 1). ${ }^{[9,10]}$

ÖÇB sonrası en sık görülen tekrarlayan instabilite nedeni cerrahi teknik hatalardır. ${ }^{[10]}$ Tünel yerleşiminin uygun olmaması ise en sık teknik hata nedenidir. Femoral tünelin anteriora yerleştirilmesi fleksiyon sırasında greft tansiyonunun artmasına, fleksiyon hareket açıkığı kaybına ve greft uzamasına neden olur. ${ }^{[11]}$ Çok posteriora açılmış femoral tünel ise diz eklemi tam ekstansiyondayken greft üzerinde tansiyonu attırır, fleksiyondayken greft çok gevşek olup görevini yapamaz ya da femoral tünel vertikal greft dizilimine neden olursa sagittal planda bir stabilite sağlarken rotasyonel olarak stabilite sağlaması tam olmaz. ${ }^{[12]}$ Aynı zamanda tibial tünel de greftin fonksiyonu ve uzun süreli sağkalımı için önemlidir. ${ }^{[9]}$ Tibial tünel açıklığı olması istenilen greft oblisitesini sağlar. Fakat çok anteriorda olan tibial tünel açıklığı ekstansiyonda notch'a sıkışır ve terminal ekstansiyon kaybına yol açar. Çok posteriorda olması da arka çapraz bağla (AÇB) sıkışması nedeniyle fleksiyon kaybıyla sonuçlanır. ${ }^{13]}$ Tibial tünel açıklığının çok medial ya da lateral tarafta olması da notch'a sıkışmasına neden olur ve iyatrojenik medial ya da lateral plato tibia kondral yüzey hasarı oluşturur. ${ }^{[14]}$

Diğer teknik hatalar; greft laksitesi ve greft tespit yetersizliğidir. Osteopeni, artmış tünel-interferans vida diverjan açısı, yetersiz tünel boyu gibi etkenler tespit

Tablo 1. Primer ÖÇB rekonstrüksiyonu başarısızık nedenleri ${ }^{[9,10]}$

- Teknik hata (en sık neden)

- Atlanmış ek bağ yaralanmaları (posterolateral köşe, IYB vb.)

- Alt ekstremite dizilim bozuklukları

- Biyolojik başarısızlık (greft inkorporasyon bozukluğu)

- Yeni travma yetersizliğine neden olabilir. Alt ekstremite dizilim bozukluğu özellikle varus deformitesi de ÖÇB greft üzerindeki stresi artırır. ${ }^{[15]}$ Posterior tibial eğimin de (slobun) ÖÇB üzerindeki strese etkisi büyüktür. Artmış tibial eğim ile ÖÇB rekonstüksiyonlarında greft yetmezliği ihtimali artmaktadır. ${ }^{[16]}$ Ameliyat öncesi varus diziliminden şüphe edilen hastalara ayakta kalça ve ayak bileği gözükecek şekilde ortoröntgenogram çekilmesi önemlidir.

Eşlik eden menisküs, kollateral bağlardaki patoloji ve yetmezlikler de primer ÖÇB rekonstrüksiyon ameliyatının başarısını önemli ölçüde etkilemektedir. Dizin ikincil stabilizatörü olması nedeniyle, menisküs yetmezliği önemli sorunlar doğurmaktadır. Yapılan çalışmalarda parsiyel medial menisküs eksizyonu yapılmış ÖÇB rekonstrüksiyonlarında medial menisküs lezyonu olmayan dizlere göre daha fazla laksite saptanmıştır. ${ }^{[17]}$

\section{HIKKÂYE VE FiZiK MUAYENE}

Primer cerrahide kullanılan greft, teknik, eşlik eden menisküs yaralanmaları, önceki travması ve varsa yeni travması çok ayrıntılı şekilde değerlendirilmelidir. Mümkünse eski cerrahi video ve kayıtlarına ulaşılmalıdır. Hasta, ameliyat sonrası ne zaman spora başlamış, ne kadar süre rehabilitasyon görmüş, bunlar da çok önemli bilgilerdir. Bu bilgiler bize başarısızlık nedenleri ve hastanın revizyondan yarar görüp görmeyeceği ile ilgili bilgi verecektir.

Lachman, ön ve arka çekmece, pivot-shift, varus-valgus stres testlerinin yanı sıra $30^{\circ}$ ve $90^{\circ}$ fleksiyonda dial testi yapılmalıdır. Posterolateral ve posteromedial yetmezliği ayırt etmek için dial testi ile tibia dikkatle değerlendirilmelidir. Hastadaki semptomların instabiliteye mi bağı olduğu yoksa instabiliteye sekonder olarak gelişen menisküs ya da kıkırdak patolojilerine mi bağlı olduğu ayrıntılı olarak değerlendirilmelidir. Kuadriseps kas atrofisine dikkat edilmelidir. Ek olarak önceki cerrahi insizyonlarda ağrıya neden olabilecek bir nöromayı ekarte edebilmek için palpe edilmelidir. Eklem hareket açıklığı da değerlendirip kısıtlılık varsa ek bir fizik tedavi ya da nihai tedavi öncesinde artroliz prosedürü uygulanmalıdır.

\section{GÖRÜNTÜLEME}

Tüm hastalarda standart diz radyografileri olmalıdır. Basarak diz ön-arka, $30^{\circ}$ fleksiyonda lateral, notch ve Merchant grafileri ayrıca alt ekstremite ortoröntgenografiler de değerlendirilmelidir. Revizyon ÖÇB ameliyatından önce primer ÖÇB ameliyatındaki tünel pozisyonlarını değerlendirmek çok önemlidir. Önceki cerrahiye ait tünel pozisyonu; ideal kullanılabilir, az yanlış 

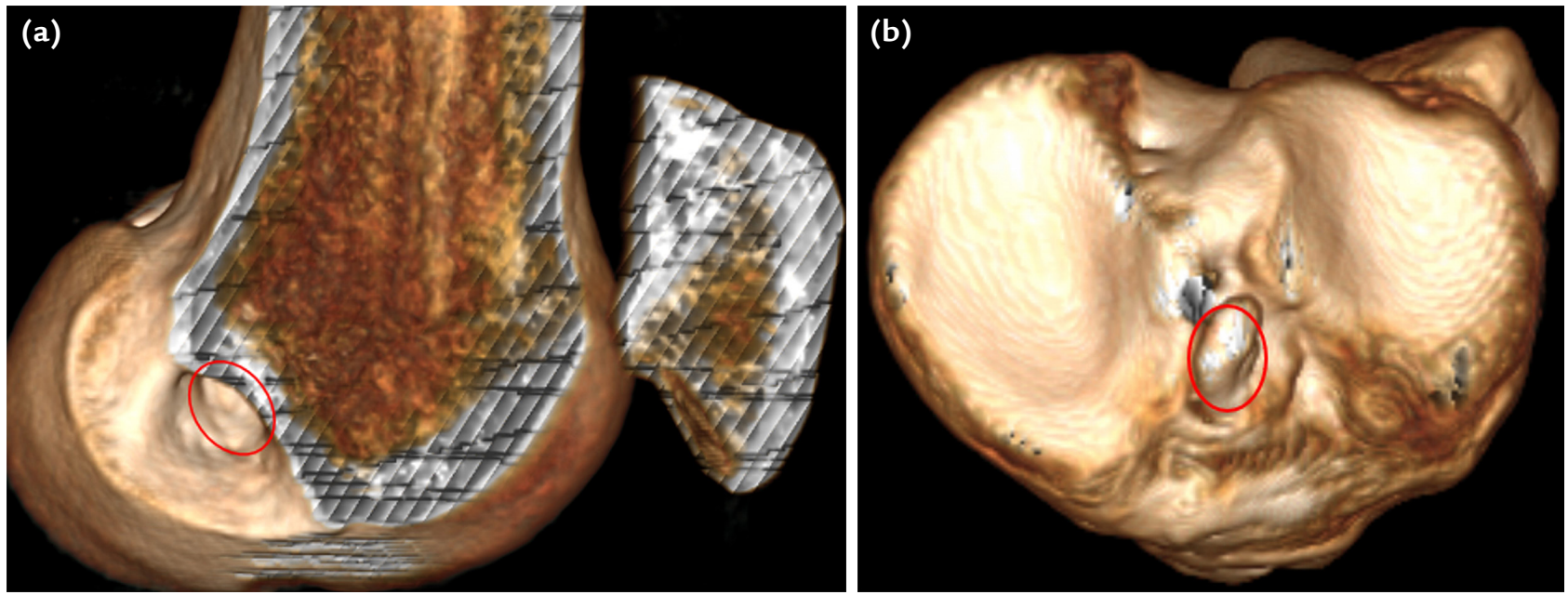

Şekil 1. a, b. Tünellerin 3D-BT ile değerlendirilmesi. Çok anteriorda femoral tünel (a); çok anteriorda femoral tünel ve ayrıca greftin kemik bölümü tünelden dışarıda (b).

yer fakat kullanılabilir, çok yanlış yer kullanılamaz ve tamamen yanlış yer olarak değerlendirilebilir. ${ }^{[18]}$ Tünel yeri ve bütünlüğü rutin görüntüleme yöntemleri ile değerlendirilemez ise tünel pozisyonunu, genişlemesini ve kemik stoğunu gösterebilecek üç boyutlu bilgisayarlı tomografi (3D-BT) ile değerlendirilmelidir (Şekil 1). Manyetik rezonans (MR) görüntüleme de tünel pozisyonu ve yumuşak doku için yardımcıdır; ancak metal yapıların artefaktı nedeniyle çok kullanışlı değildir.

\section{GREFT SEÇIMi}

Primer veya revizyon ÖÇB rekonstrüksiyon ameliyatları için mükemmel denilecek bir greft yoktur. Allogreft veya otogreft kullanılabilir. Birbirlerinden farklı avantaj ve dezavantajları mevcuttur. Allogreftler donör saha morbiditesini ortadan kaldırır ve özellikle çoklu bağ (multi-ligament) yaralanması olan hastalarda ve revizyon hastalarında tercih edilmektedir. Özellikle aşil tendon allogrefti geniş kemik blok ve tendon çapıyla kesişen tünelleri tek aşamada doldurmak için tercih edilmektedir. Allogreftler özellikle de önceki ameliyattan kaynaklı otogreft seçenekleri kısitlıysa tercih edilir. ${ }^{[19]}$ Ancak, allogreftlerin inkorporasyonu otogreftlere göre daha yavaş ve zayıftır. Bu nedenlerle, allogreftlerde rerüptür oranı otogreftlere göre daha fazla ve klinik başarısı daha azdır. ${ }^{[20]}$

Allogreftlerdeki bu risk faktörleri nedeniyle genellikle otogreftlerin kullanılması tercih edilmektedir. Aynı (ipsilateral) veya karşı taraftaki (kontralateral) kemikpatellar tendon-kemik, hamstring veya kuadriseps kemik-tendon otogreftleri tercih edilebilir. Kemik greftler daha çok tünel genişlemesi olan revizyon hastalarında seçilmekle birlikte, çok merkezli ÖÇB revizyon kohort çalışmasında (MARS) yumuşak doku otogreftleriyle kemik otogreftleri arasında yeniden kopma ya da klinik başarıda bir fark görülmemiştir. ${ }^{[20]}$

\section{TÜNEL GENiŞLEMESi - KEMIK GREFTLEME}

Tünel genişlemesi ve kemik kaybı revizyon cerrahisi öncesi değerlendirilmesi gerekli en önemli parametredir. Ameliyat öncesi değerlendirilmeli ve tek aşamalı revizyon için bir engel teşkil edip etmediğine karar verilmelidir. Eğer tüneller fazlasıyla genişlediyse ve yerleşim yeri tam ya da parsiyel uygun ise rijit tespit konusunda zorluk yaşanabilir. ${ }^{[11]}$ Bu nedenden ötürü, çift aşamalı cerrahi, diverjan tünel açılması, tünelin tendon greft ile birlikte kemik greft ya da interferans vida ile desteklenmesi gibi seçeneklerin kararı ameliyat öncesi verilmelidir (Şekil 2). Özellikle 14-15 mm üzerinde genişliğe sahip tüneller varlığında çift aşamalı cerrahi (greftleme sonrası revizyon) önerilmektedir. Genişlemiş ancak yerleşimi uygun olmayan tünel varlığında tünel yok sayılarak yeni bir tünel açılabilir. ${ }^{[5]}$

Tünellerin yerleşimi ve genişliği kabul edilebilir sınırlarda ise, tünellerdeki implantlar gerekli görülürse çıkartılmalı ve tünel duvarları fibröz yapılardan arındırılmalıdır. Eğer tünel çapı çok geniş ise mevcut giriş yerine en yakın yerden farklı bir tünel açılmalıdır. Bazen bu iki tünel birbirine çok yakın olabilir. Bu gibi zamanlarda eski tünel kemik grefti ile greftlenmeli, yaklaşık 3-6 ay sonra kaynama gerçekleştikten sonra revizyon cerrahisi uygulanarak yeni tüneller açılmalıdır. ${ }^{[21]}$ 

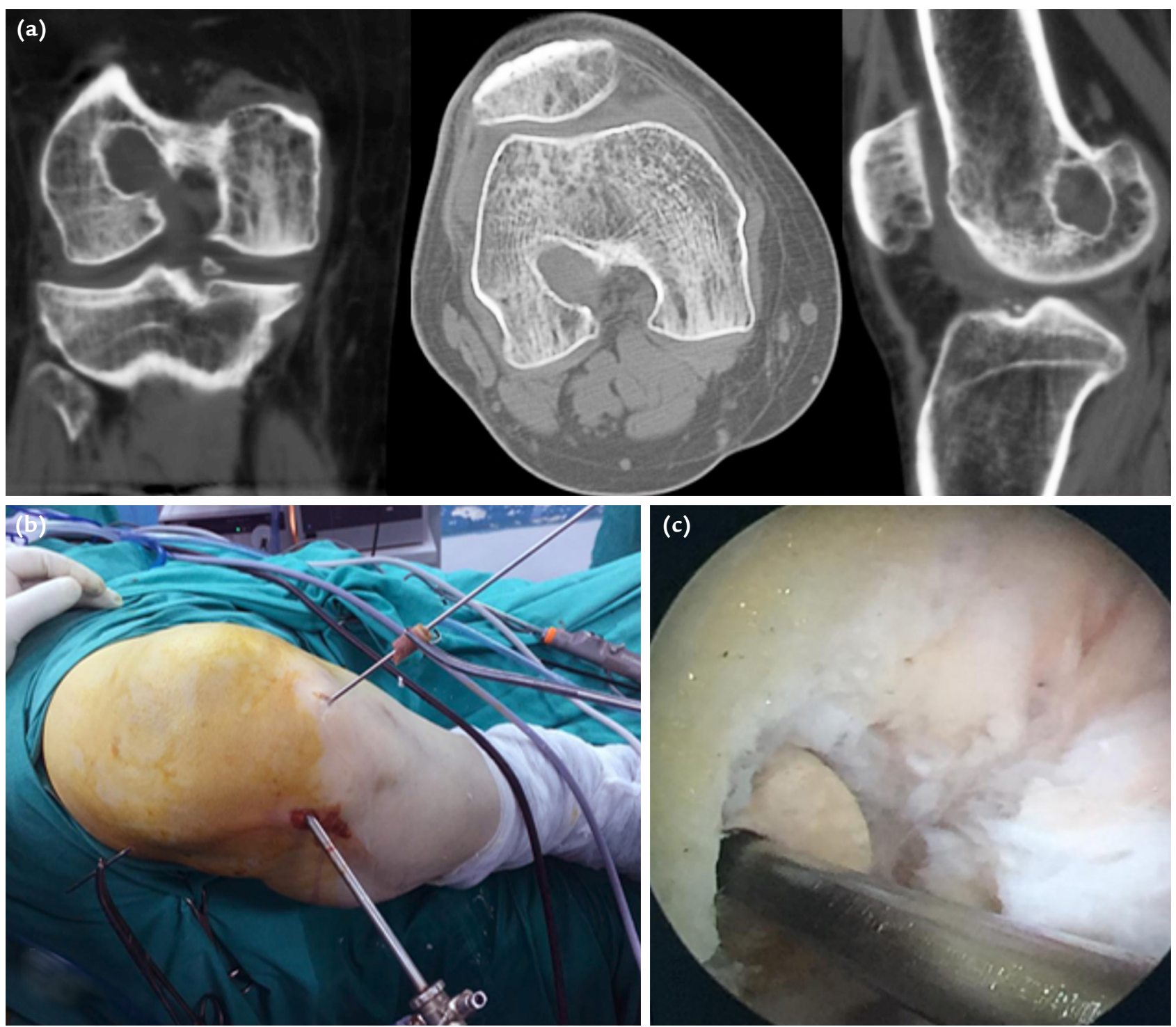

Şekil 2. a-c. Genişlemiş femoral tünel bilgisayarlı tomografi görüntüleri (a). Anteromedial portalden kemik greftin tünele gönderilmesi (b). Kemik greftin tünelin içindeki görüntüsü (c).

\section{CERRAHI TEKNIK}

Revizyon ÖÇB ameliyatına karar verilen hastalar bir gün önce servise yatırılarak gerekli ameliyat öncesi hazırlıkları yapılır. Her revizyon ameliyatından önce eğer penisilin alerjisi yoksa hastalara 1. kuşak sefalosporinler profilaktik olarak turnike şişirilmeden yarım saat önce verilir. Ameliyat genel anestezi ya da rejyonel anestezi ile gerekli kas gevşemesi de sağlanarak yapılabilir. Anestezi sonrası instabilite testleri tekrarlanır. Cerrahi cilt temizliğini takiben hasta steril olarak örtülür. Eğer karşı bacaktan greft alınacaksa hastanın iki bacağı da steril olarak hazırlanır. Örtme işlemi tamamlandıktan sonra, tanısal artroskopi yapmak amacıyla, hastanın bacağına boşaltıcı bandaj uygulaması sonrası sistolik basıncın $100 \mathrm{mmHg}$ üstünde olacak şekilde havalı turnike uygulanır. Tünel pozisyonları, eklem içi patolojilerin varlığı değerlendirilir; eğer uygun ise greft almaya geçilip revizyon ÖÇB ameliyatına başlanır. Bu sırada saptanacak menisküs lezyonları ya da kondral lezyonlar gerekli şekilde tedavi edilir. Eğer karşı bacaktan greft alınacak ise, o taraftaki havalı turnike şişirilmeden önce diğer bacaktaki turnike indilir, karşı taraftaki işlem bittikten sonra tekrar şişirilir. (Şekil 3). 

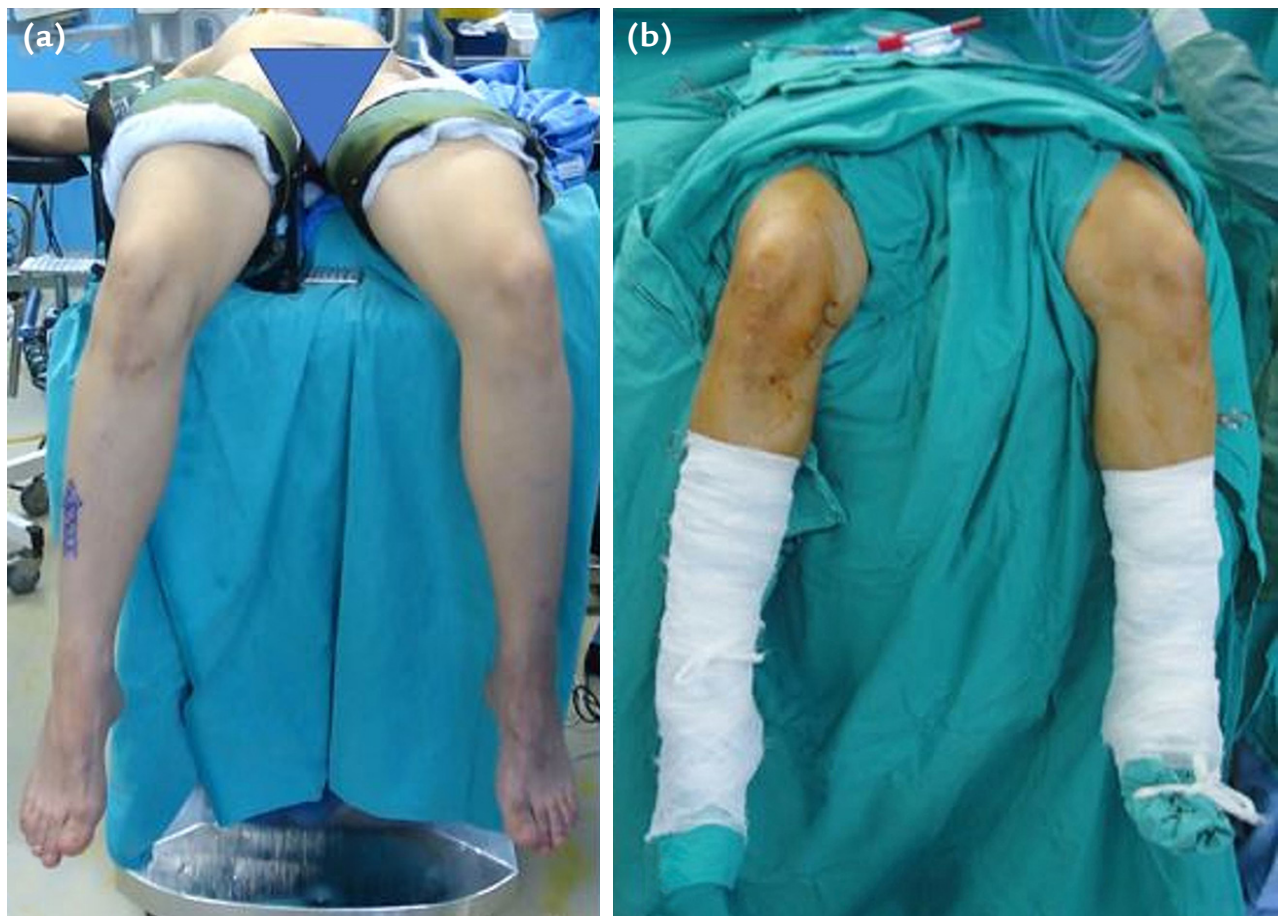

Şekil 3. a, b. Hastanın ameliyat masasında hazırlanışı. Her iki bacağa turnike uygulanır (a); ÖÇB revizyonu yapılacak diz ile karşı (kontralateral) diz açık bırakılır (b).
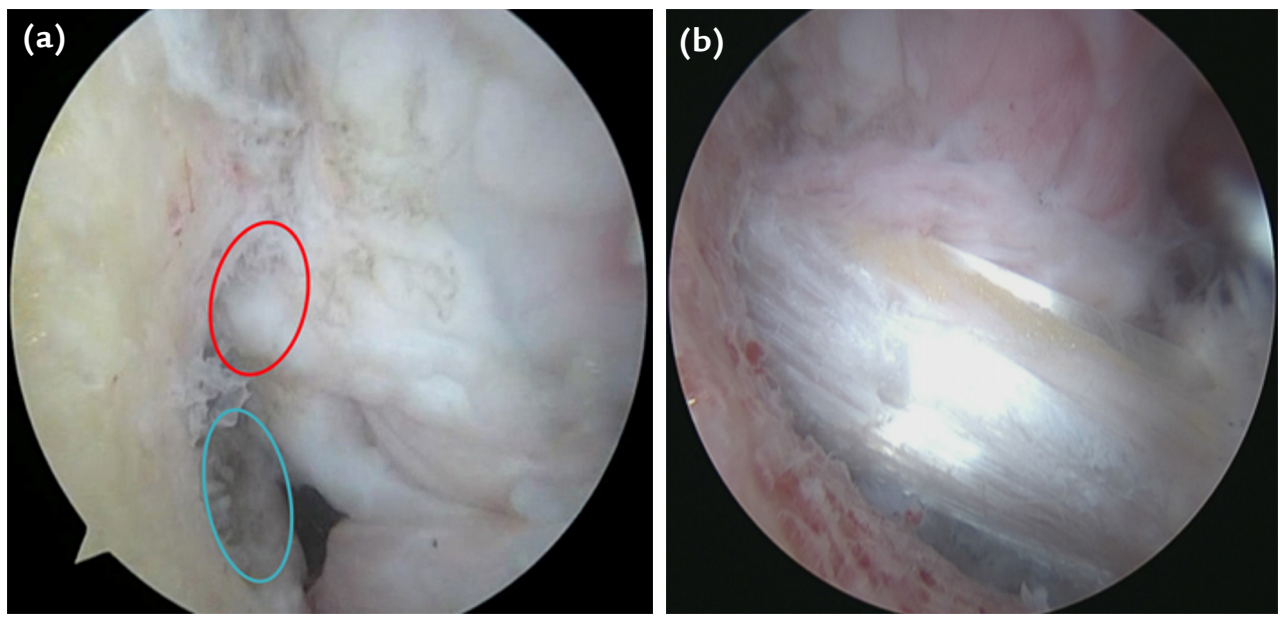

Şekil 4. a, b. Çok süperiorda eski femoral tünel (kırmızı daire), revizyonda açılmış yeni femoral tünel (mavi daire) (a). Yeni femoral tünelde greft (b).

\section{Femoral ve Tibial Tünellerin Hazırlanması}

Ameliyat öncesi eski ameliyatların tespit materyallerini değerlendikten sonra ve tüneller hazırlanmadan önce yapılan tanısal artroskopide eklem içerisinde ya da açacağımız tünel ile çakışacak bir tespit materyali ya da sentetik greft varlığında tünel açmadan önce bu materyaller çıkartılır. Tüneldeki vida ya da sentetik greft çıkartıldıktan sonra tünel fibröz dokulardan temizlenir. Bu gibi vida çıkarma işlemlerinde, tibial tünelden çıkacak eklem içi su kaçağını önlemek amacıyla ilk olarak femoral tünelden başlanır. Debridman sonrası yeterli kemik stoğu mevcut ise tek aşamalı revizyon ÖÇB ameliyatına başlanır. Transportal (anteromedial), tamamı içeride teknik veya modifiye transtibial teknik tünelleri açmak için kullanılabilir (Şekil 4). ${ }^{[22]}$ 

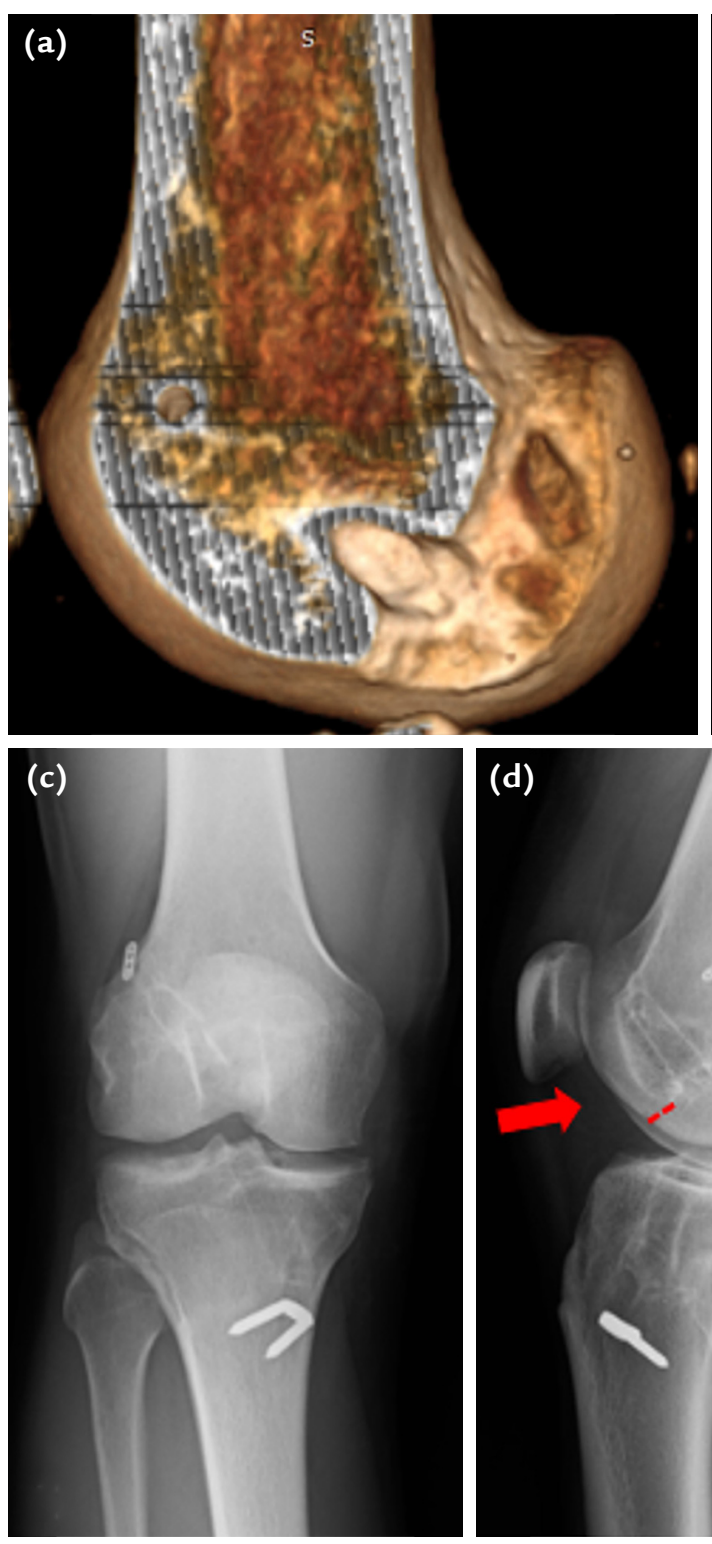

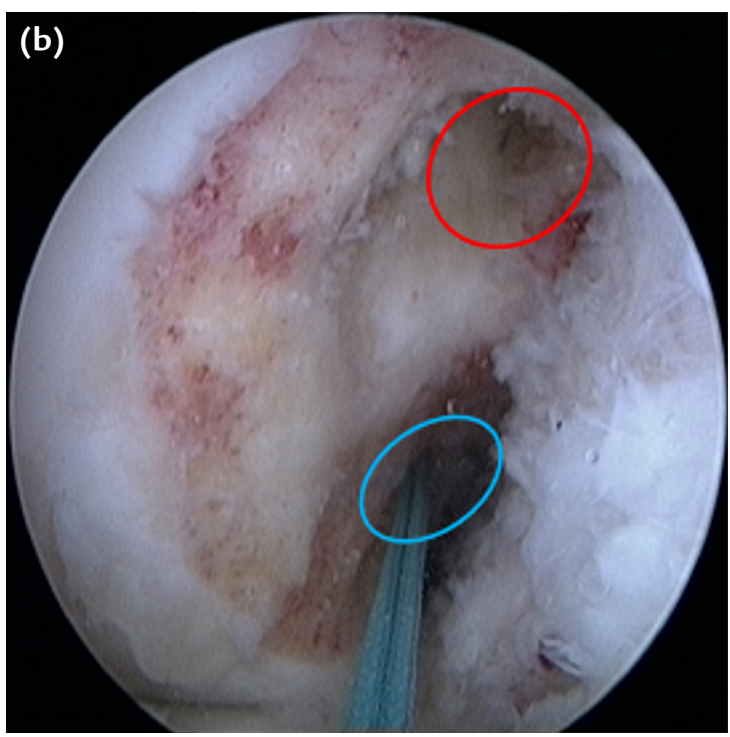

Şekil 5. a-d. 3D-BT çok anterior ve süperiorda femoral tünel, yeni tünel ayak izine açılmış (a). Tünellerin artroskopik görüntüsü (kırmızı daire, eski tünel; mavi daire, yeni tünel) (b). Ameliyat sonrası direkt grafiler, çok süperiordaki femoral tünelin sebep olduğu Blumensaat çizgisinin kesik görüntüsü (kırmızı noktalı çizgi, c, d).

\section{Tünel Senaryoları}

Hastaların ÖÇB rekonstrüksiyon ameliyatı nedeniyle, mevcut olan tünellerin yeri ve genişliğine göre çeşitli senaryolarla karşılaşılabilir. Bunlar ${ }^{[23]}$ :

- Femoral tünel, eğer eski tünelden bir tünel çapından daha anteriorda veya süperiorda ise (yanlış tünel) eski tünelden bağımsız olarak posteriora veya inferiora yeni bir tünel açılabilir (Şekil 5).

- Eski femoral tünel hafif anterior yerleşimli (doğru tünel yeri ile kısmen örtüşen) ya da yeni açılacak tünel ile birleşip geniş bir tünel oluşma riski varsa, doğru yerdeki eski tünel implant çıkarıldıktan sonra geniş bir tünel oluşabilir. Böyle bir senaryoda, geniş tünel kemik grefti ile greftlenerek iki aşamalı cerrahiye geçilir ya da tek aşamalı çeşitli teknikler denenebilir[ ${ }^{5]}$ :

- Küçük çaplı hamstring greftleri kullanılır ve daha küçük çaplı bir greft posteriora yerleştirilir. Rosenberg'in 'bisocket' tekniğinde iki adet $6 \mathrm{~mm}$ çapında tünel ile hamstring tendonları kortikal askı ile kortekse tespit edilir. ${ }^{[9,23]}$

- İmplant çıkarılır, eski tünel posteriora genişletilir, ardından büyük kemik greftli allogreftler kullanılır. Tendon tespiti için büyük çaplı interferans vidaları kullanılır. 

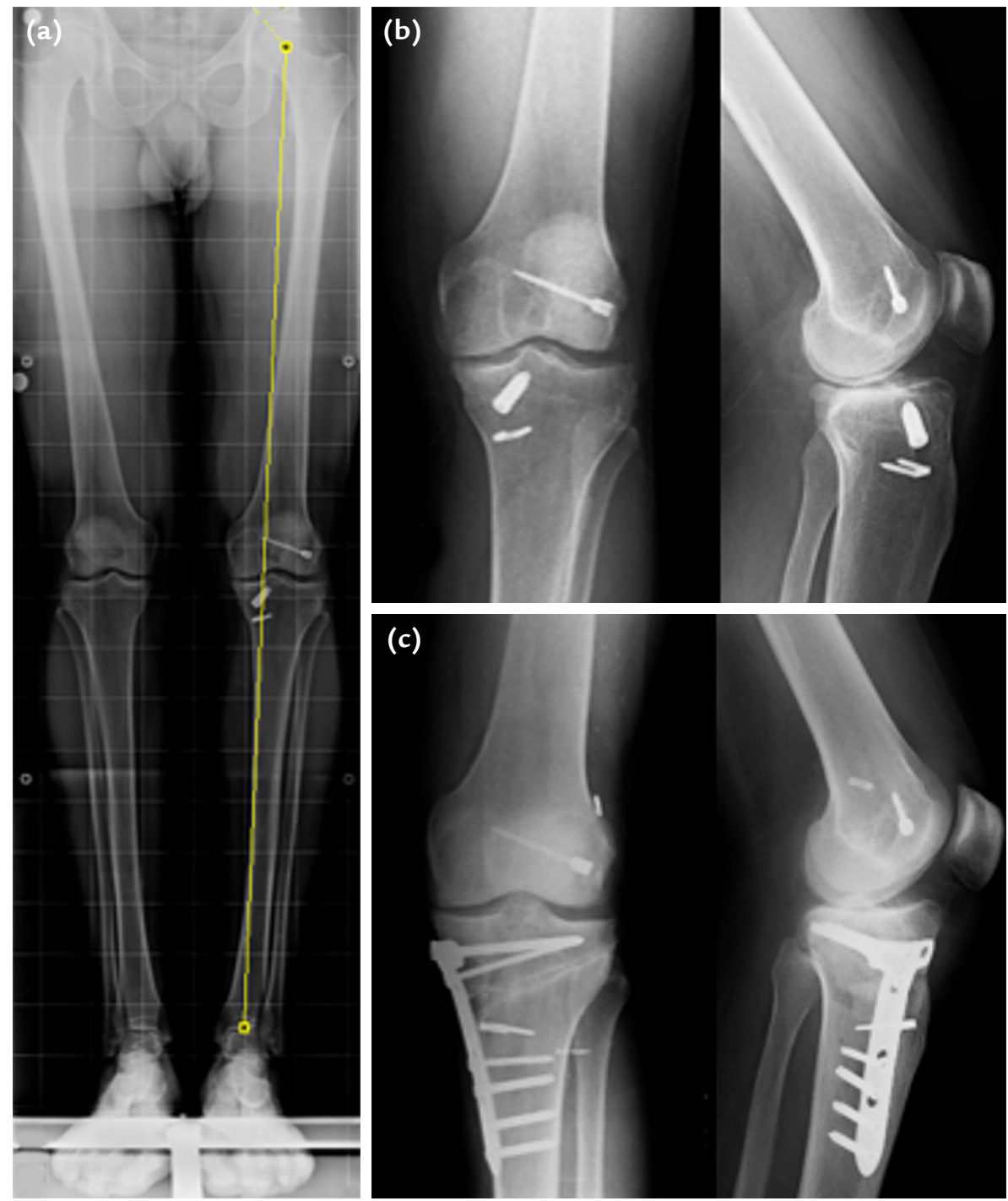

Şekil 6. a-c. Alt ekstremite ortoröntgenogram (a). Diz direkt grafileri Kellgren-Lawrence Evre 3 artroz (b). Medial açık kama yüksek tibia ostetomisi ve revizyon ÖÇB rekonstrüksiyonu sonrası diz direkt grafileri (c).

- Yeni tünel açıldıktan sonra, eski tünele interferans vidası ve yeni tünelde greft interferans vidası ile tespit edilir ve stabilite sağlanır (stacked interferans vidası).

- Tendon grefti yerleştirildikten sonra geniş tünel kemik allogreftlerle greftlenir ve sonrasında tünel dışı tespiti sağlanır (crosspin, kortikal askı, pull vida, sütür post).

- İki insizyon tekniği ile dıştan içe, tünel açıklığı aynı doğrultusu farklı tünel açılır.

- Eğer femoral tünel posterior yerleşimli ve posterior korteks intakt değil ise:
- Greft için distalde posterior duvarı defektli bir tünel açılır, tespit için kortikal askı ya da crosspin kullanılır.

- Greft 'over the top' yerleştirilir ve lateral femoral kortekse tespit edilir.

- İki insizyon tekniği ile dıştan içe tünel açıklığı aynı doğrultusu farklı tünel açılır.

- Tibiada, en fazla anteriora açılmış tünel görülür. Eğer bir tünel çapından fazla anteriorda (yanlış tünel) ise, posterioruna yeni bir tibial tünel açılarak işleme devam edilir. 
- Tibial tünel hafif anteriorda (doğru tünel ile kesişen tünel) ise, tünel olması gereken yere yani posteriora doğru genişletilir. Ardından eklem dışı (ekstra-artiküler) tibial tespit sağlanır. Eski tüneli doldurmak için ise, eriyebilir interferans vidası veya kemik blok allogreft konulur ve defekt doldurulur.

- Eğer tibial tünel hafif posteriorda (doğru tünel ile kesişen tünel) ise ${ }^{[24]}$ :

- Tünel anteriora büyütülür ve büyük kemik bloğu ya da eriyebilir vida ile eski tünel doldurulur.

- Büyük kemik grefti allogreft yerleştirilir ve greftin korteks yeri posteriora çevrilir.

- ÖçB'nin kuvvet kolu doğrultusunda greftin posteriora vektörü olduğu için iki aşamalı cerrahi planlanır.

\section{Notchplasti (İnterkondiler Aralığın Temizliği)}

İnterkondiler aralığın temizliği iki nedenden dolayı yapılır. İnterkondiler aralığı (notch bölgesi) daralmış olarak değerlendirilen hastalarda sınırlı notchplasti uygulanır.

- Özellikle kronik ÖÇB yetmezliği olan olgularda interkondiler aralıktaki osteofitleri ve yumuşak dokuları temizlemek, interkondiler çentiğin yapısal olarak dar olduğu durumlarda çentiği genişletmek amaçlı uygulanır.

- Lateral femoral kondilin posterior korteksini tespit etmek ve böylece 'over the top'u bularak femoral tüneli doğru yerleştirmek amaçlı yapılır.

\section{Greftin Tespiti}

Greft tespiti sabit loop'lu kortikal askı, ayarlanabilir loop'lu kortikal askı, crosspin, interferans vidası (eriyebilir-metal) gibi teknikler kullanılarak yapılabilir. Bunun dışında özellikle tibial tarafta staple ve sütür post gibi ikincil tespitler gerekebilir. Revizyon ÖÇB cerrahisinde özellikle tünel senaryosu, kemik stok durumu ve kullanılan grefte göre karar verilmelidir. MARS kohortunda hem tibiada hem femurda metal interferans vidaların fonksiyonel skorlarının daha tatmin edici olduğu gösterilmiştir. ${ }^{[25]}$

\section{Ek İşlemler}

Bazı durumlarda, revizyon cerrahisinin başarısını sağlamak için ek prosedürler gerekli olacaktır. Menisküs yırtığı, dizin stabilitesine katkısından dolayı ve mümkünse onarılmalıdır. Subtotal ya da total menisektomi sonrası görülen menisküs yetmezliği menisküs transplantasyonu gerektirebilir. Alt ekstremite dizilimi değerlendirildiğinde aşırı tibial slop greft üzerine binen yükleri artıracağı için anterior kapayıcı kama ostetomisi planlanmalıdır. Ayrıca tibia vara mevcutsa proksimal tibia ostetomisi rotasyonel stabilite için önemlidir (Şekil 6). Ek olarak anterolateral kompleks yaralanması olan, rotasyonel profil bozukluğu olan, Grade 3 pivot shift'i olan dizlerde ekstra-artiküler tenodez veya anterolateral bağ rekonstrüksiyonu yararIı olacaktır. ${ }^{[26]}$

\section{REHABILITASYON}

Revizyon sonrası rehabilitasyonun amacı; hastayı hızlı ve güvenli bir şekilde yaralanma öncesindeki fonksiyonel seviyesine getirmektir. Hızlandırılmış rehabilitasyon programlarının konservatif programlara göre daha düşük maliyet, hızlı greft iyileşmesi, spora erken dönüş, eklem hareket açıklığının ve diz fonksiyonlarının daha erken kazanılması, daha erken kas gücünün sağlanması ve daha az artrofibröz görülmesi gibi avantajları vardır. Bu nedenle günümüzde hızlandırılmış rehabilitasyon programları tercih edilmektedir. Rehabilitasyon protokolü hastaya ameliyat öncesi dönemde öğretilmelidir. Böylece hastanın uyumu sağlanmış olur. Cerrahi öncesi dönemde ağrı, şişlik ve enflamasyonu azaltmak, tam EHA sağlamak, hastayı normal yürüyüş paternine geri getirmek, kas atrofisini engellemek amaçlanır. ${ }^{27]}$

Primer ÖÇB rekonstrüksiyonundan farklı olarak ÖÇB revizyonunun rehabilitasyon programı daha yavaştır. Rehabilitasyon programı hastaya özel olmalıdır. Bu program ameliyat içinde yapılmış bir menisküs dikişi ya da yüksek (proksimal) tibial ostetomi benzeri ek işlemlere göre değişebileceği gibi hastanın fonksiyon ve kas kurvetlerine göre de değişebilir.

\section{ISTANBUL TIP FAKÜLTESI TECRÜBESi}

2002 ve 2018 yılları arasında revizyon ÖÇB uyguladığımız hastaların (44 hasta / $46 \mathrm{diz}$ ), geriye dönük değerlendirmesinde; hastalarda başarısızlık nedeni, 27 hastada teknik hata, 19 hastada travmaydı. Ortalama takip süresi 77,9 ay (7 ay - 206 ay) idi. Ortalama Tegner aktivite skoru; ilk yaralanma öncesi 7,3, rekonstrüksiyon sonrası 6,02 iken, revizyon sonrası 6 olarak değerlendirildi. Modifiye Cincinnati değerlendirme sistemi skoru ortalama 79,1-iyi (30$100)$, Tegner-Lysholm diz skorlaması ise 80,2-orta (30-100) idi. Sonuçlara etki eden etkenler araştırıldığında; greft kalınlığı, artan femoral tünel oblisitesi ile subjektif skorlar arasında pozitif korelasyon bulunurken $(p<0,05)$, menisküs yaralanması varlığı ve VKi (vücut kitle indeksi) ile ise negatif korelasyon saptandı $(\mathrm{p}<0,05)$. 


\section{ÖÇB REVIZYON CERRAHISI SONRASI KLINIIK SONUÇLAR}

Mevcut literatürün çoğu hasta popülasyonları, primer ve revizyon cerrahi teknikler, eşlik eden bağ yaralanmaları ve revizyon sırasında yapılan ek prosedürler açısından heterojen olması nedeniyle, rapor edilen sonuçların genellenmesi zor olmaktadır. Literatürde revizyon ÖÇB rekonstrüksiyonunu takip eden sonuçların primer ÖÇB rekonstrüksiyonundan daha düşük olduğu, daha düşük spora dönüş oranları ve spora dönüş için uzun bir zaman dilimi olduğu iyi bilinmektedir. ${ }^{[28,29]}$ Revizyon sırasında menisküs lezyonu olmayan, ek ligament ya da kıkırdak lezyonu olmayan hastalar, bu gibi ek lezyonları olan ya da ek cerrahi işlem uygulanması gerekmiş hastalara göre daha iyi klinik sonuçlara sahiptirler. ${ }^{[30]}$

Anand ve ark., ilk yaralanma öncesi aktif olarak spor yapan 109 hastalık beş yıl takipli ÖÇB revizyonu serilerinde, hastaların \%46'sının primer yaralanma sonrası aktivite seviyelerine ulaştığını bildirmişlerdir. Profesyonel sporcuların ve 25 yaş altı genç hastaların spora dönüş oranlarının daha fazla olduğunu bildirmişlerdir. ${ }^{[31]}$ Franceschi ve ark., iki aşamalı cerrahi sonrası beş yıllık takipler sonucunda tatmin edici sonuçlar bildirmişlerdir. ${ }^{[32]}$

Mitchell ve ark., 39 tek aşama, 49 iki aşamalı hastanın yer aldığı geriye dönük kohort çalışmasında, başarısızlık oranlarında ve subjektif skorlamalarda istatistiksel bir fark olmadığını belirtmişlerdir. ${ }^{[33]}$ ÖÇB revizyonlarının başarısızlığı literatürde \%7-10 arasında dökümante edilmiştir. ${ }^{[34-36]}$

Birçok yayında, revizyon ÖÇB ameliyatında primer ÖÇB rekonstrüksiyonuna kıyasla daha yüksek başarısızlık oranı olduğu ve sonuçların daha kötü olduğu bildirilmiştir. ${ }^{[37]}$ Noyes ve Barber-Westin, 2001 yılında yayımladıkları kendi ÖÇB revizyon serilerinde, greft başarısızığı oranını \%24 olarak bildirmişlerdir. ${ }^{[36]}$

\section{SONUÇ}

ÖÇB revizyonu planlanan hastaların ameliyat öncesi değerlendirilmesi, revizyonun başarısı için çok önemlidir. Önceki ameliyatı ve ÖÇB rekonstrüksiyon başarısızlık nedeni çok iyi değerlendirilmelidir. Eski implant varlığı, tünel genişlemesi veya kesişmesi, greft seçimi ve ek yaralanmalar gibi, primer cerrahiye göre daha kompleks sorunlar ile karşılaşılabilir. Genel olarak tatmin edici sonuçlara ulaşılsa da primer ÖÇB sonrası sonuçlara ulaşabilmek zordur. Bu nedenle, hastalara gerçekçi beklentileri bildirmek önemlidir.

\section{KAYNAKLAR}

1. Marx RG, Parker RD, Matava MJ, Sekiya JK. Cruciate and Collateral Ligament Injuries (Chap. 109). In: Lieberman JR, editor. Comprehensive Orthopaedic Review. USA: AAOS; 2009. pp.1113-31.

2. Granan L-P, Forssblad M, Lind M, Engebretsen L. The Scandinavian ACL registries 2004-2007: baseline epidemiology. Acta Orthop 2009;80(5):563-7. Crossref

3. Janssen KW, Orchard JW, Driscoll TR, van Mechelen W. High incidence and costs for anterior cruciate ligament reconstructions performed in Australia from 2003-2004 to 2007-2008: time for an anterior cruciate ligament register by Scandinavian model? Scand J Med Sci Sports 2012;22(4):495-501. Crossref

4. Mall NA, Chalmers PN, Moric M, Tanaka MJ, Cole BJ, Bach BR Jr, Paletta GA Jr. Incidence and trends of anterior cruciate ligament reconstruction in the United States. Am J Sports Med 2014;42(10):2363-70. Crossref

5. Bach BR. Revision anterior cruciate ligament surgery. Arthroscopy 2003;19(10):14-29. Crossref

6. Kraeutler MJ, Bravman JT, McCarty EC. Bone-patellar tendonbone autograft versus allograft in outcomes of anterior cruciate ligament reconstruction: a meta-analysis of 5182 patients. Am J Sports Med 2013;41(10):2439-48. Crossref

7. Johnson D, FuF. Anterior cruciate ligament reconstruction: why do failures occur? Instr Course Lect 1994;44(11):391-406.

8. Uribe JW, Hechtman KS, Zvijac JE, Tjin-A-Tsoi EW. Revision anterior cruciate ligament surgery: experience from Miami. Clin Orthop Relat Res 1996;325:91-9. Crossref

9. Getelman $\mathrm{MH}$, Friedman MJ. Revision anterior cruciate ligament reconstruction surgery. J Am Acad Orthop Surg 1999;7(3):189-98. Crossref

10. Jaureguito JW, Paulos LE. Why grafts fail. Clin Orthop Relat Res 1996;325:25-41. Crossref

11. Kamath GV, Redfern JC, Greis PE, Burks RT. Revision anterior cruciate ligament reconstruction. Am J Sports Med 2011;39(1):199-217. Crossref

12. Carson EW, Anisko EM, Restrepo C, Panariello RA, O'Brien SJ, Warren RF. Revision anterior cruciate ligament reconstruction-etiology of failures and clinical results. J Knee Surg 2004;17(03):127-32. Crossref

13. Allen CR, Giffin JR, Harner CD. Revision anterior cruciate ligament reconstruction. Orthop Clin North Am 2003;34(1):79-98. Crossref

14. Muneta $T$, Yamamoto $H$, Ishibashi $T$, Asahina S, Murakami $S$, Furuya K. The effects of tibial tunnel placement and roofplasty on reconstructed anterior cruciate ligament knees. Arthroscopy 1995;11(1):57-62. Crossref

15. Noyes FR, Barber-Westin SD, Hewett TE. High tibial osteotomy and ligament reconstruction for varus angulated anterior cruciate ligament-deficient knees. Am J Sports Med 2000;28(3):282-96. Crossref

16. Christensen JJ, Krych AJ, Engasser WM, Vanhees MK, Collins MS, Dahm DL. Lateral tibial posterior slope is increased in patients with early graft failure after anterior cruciate ligament reconstruction. Am J Sports Med 2015;43(10):2510-4. Crossref

17. Shelbourne KD, Gray T. Results of anterior cruciate ligament reconstruction based on meniscus and articular cartilage status at the time of surgery: five-to fifteen-year evaluations. Am J Sports Med 2000;28(4):446-52. Crossref

18. Yiğit Cirdi SE, Onur Başçı, Mustafa Karahan. Ön Çapraz Bağ Rekonstrüksiyonu Revizyonu. İçinde: Aşık M, editor. Diz Eklemi Bağ ve Tendon Sorunları Güncel Yaklaşımlar. İstanbul: İstanbul Tıp Kitabevleri; 2016. pp.189-99. 
19. Wright RW, Huston LJ, Spindler KP, Dunn WR, Haas AK, Allen CR, Cooper DE, DeBerardino TM, Lantz BBA, Mann BJ, Stuart MJ. Descriptive epidemiology of the Multicenter ACL Revision Study (MARS) cohort. Am J Sports Med 2010;38(10):1979-86. Crossref

20. MARS Group; Wright RW, Huston LJ, Haas AK, Spindler KP, Nwosu SK, Allen CR, Anderson AF, Cooper DE, DeBerardino TM, Dunn WR, Lantz BBA, Stuart MJ, Garofoli EA, Albright JP, Amendola AN, Andrish JT, Annunziata CC, Arciero RA, Bach BR, Baker CL, Bartolozzi AR, Baumgarten KM, Bechler JR, Berg JH, Bernas GA, Brockmeier SF, Brophy RH, CA Joseph B, Butler JB, Campbell JD, Carey JL, Carpenter JE, Cole BJ, Cooper JM, Cox CL, Creighton RA, Dahm DL, David TS, Flanigan DC, Frederick RW, Ganley TJ, Gatt CJ, Gecha SR, Giffin JR, Hame SL, Hannafin JA, Harner CD, Harris NL, Hechtman KS, Hershman EB, Hoellrich RG, Hosea TM, Johnson DC, Johnson TS, Jones MH, Kaeding CC, Kamath GV, Klootwyk TE, Levy BA, Ma CB, Maiers GP, Marx RG, Matava MJ, Mathien GM, McAllister DR, McCarty EC, McCormack RG, Miller BS, Nissen CW, O'Neill DF, Owens BD, Parker RD, Purnell ML, Ramappa AJ, Rauh MA, Rettig AC, Sekiya JK, Shea KG, Sherman OH, Slauterbeck JR, Smith MV, Spang JT, Svoboda SJ, Taft TN, Tenuta JJ, Tingstad EM, Vidal AF, Viskontas DG, White RA, Williams JS, Wolcott ML, Wolf BR, York JJ. Effect of graft choice on the outcome of revision anterior cruciate ligament reconstruction in the Multicenter ACL Revision Study (MARS) Cohort. Am J Sports Med 2014;42(10):2301-10. Crossref

21. Mathew CJ, Palmer JE, Lambert BS, Harris JD, McCulloch $P C$. Single-stage versus two-stage revision anterior cruciate ligament reconstruction: a systematic review. J ISAKOS 2018;3(6):345-51. Crossref

22. Robin BN, Jani SS, Marvil SC, Reid JB, Schillhammer CK, Lubowitz JH. Advantages and Disadvantages of Transtibial, Anteromedial Portal, and Outside-In Femoral Tunnel Drilling in Single-Bundle Anterior Cruciate Ligament Reconstruction: A Systematic Review. Arthroscopy. 2015;31(7):1412-7. Crossref

23. Gönç U. Revizyon Ön Çapraz Bağ Cerrahisi. İçinde: Tandoğan NR, editor. Diz Bağ Yaralanmaları. Ankara: Tuna Matbaası; 2013.

24. Allen CR, Giffin JR, Harner CD. Revision anterior cruciate ligament reconstruction. Orthop Clin North Am 2003;34(1):79-98. Crossref

25. MARS Group; Allen CR, Anderson AF, Cooper DE, DeBerardino TM, Dunn WR, Haas AK, Huston LJ, Lantz BBA, Mann B, Nwosu SK, Spindler KP, Stuart MJ, Wright RW, Albright JP, Amendola AN, Andrish JT, Annunziata CC, Arciero RA, Bach BR Jr, Baker CL 3rd, Bartolozzi AR, Baumgarten KM, Bechler JR, Berg JH, Bernas GA, Brockmeier SF, Brophy RH, Bush-Joseph CA, Butler JB 5th, Campbell JD, Carey JL, Carpenter JE, Cole BJ, Cooper JM, Cox CL, Creighton RA, Dahm DL, David TS, Flanigan DC, Frederick RW, Ganley TJ, Garofoli EA, Gatt CJ Jr, Gecha SR, Giffin JR, Hame SL, Hannafin JA, Harner CD, Harris NL Jr, Hechtman KS, Hershman EB, Hoellrich RG, Hosea TM, Johnson DC, Johnson TS, Jones MH, Kaeding CC, Kamath GV, Klootwyk TE, Levy BA, Ma CB, Maiers GP 2nd, Marx RG, Matava MJ, Mathien GM, McAllister DR, McCarty EC, McCormack RG, Miller BS, Nissen CW, O'Neill DF, Owens BD, Parker RD, Purnell ML, Ramappa AJ, Rauh MA, Rettig AC, Sekiya JK, Shea KG, Sherman OH, Slauterbeck JR, Smith MV, Spang JT, Svoboda SJ, Taft TN, Tenuta JJ, Tingstad EM, Vidal AF, Viskontas DG, White RA, Williams JS Jr, Wolcott ML, Wolf BR, York JJ. Surgical Predictors of Clinical Outcomes After Revision Anterior Cruciate Ligament Reconstruction. Am J Sports Med 2017;45(11):2586-94. Crossref
26. Lee DW, Kim JG, Cho SI, Kim DH. Clinical Outcomes of Isolated Revision Anterior Cruciate Ligament Reconstruction or in Combination with Anatomic Anterolateral Ligament Reconstruction. Am J Sports Med 2019;47(2):324-33. Crossref

27. Wright RW, Haas AK, Anderson J, Calabrese G, Cavanaugh J, Hewett TE, Lorring D, McKenzie C, Preston E, Williams G; MOON Group. Anterior cruciate ligament reconstruction rehabilitation: MOON guidelines. Sports Health 2015;7(3):239-43. Crossref

28. Wang B, Lee KT. Results of revision anterior cruciate ligament reconstruction using a transportal technique. Acta Orthop Belg 2015;81(4):752-8.

29. Erickson BJ, Cretanovich GL, Frank RM, Riff AJ, Bach BR Jr. Revision ACL Reconstruction: A Critical Analysis Review. JBJS Rev 2017;5(6):e1. Crossref

30. MARS Group; Wright RW, Huston LJ, Nwosu SK, Haas AK, Allen CR, Anderson AF, Cooper DE, DeBerardino TM, Dunn WR, Lantz BA, Mann B, Spindler KP, Stuart MJ, Albright JP, Amendola A, Andrish JT, Annunziata CC, Arciero RA, Bach $\mathrm{BR}$, Baker CL, Bartolozzi AR, Baumgarten KM, Bechler JR, Berg JH, Bernas GA, Brockmeier SF, Brophy RH,CA BushJoseph, Butler JB, Campbell JD, Carey JL, Carpenter JE, Cole BJ, Cooper JM, Cox CL, Creighton RA, Dahm DL, David TS, Flanigan DC, Frederick RW, Ganley TJ, Garofoli EA, Gatt CJ, Gecha SR, Giffin JR, Hame SL, Hannafin JA, Harner CD, Harris NL, Hechtman KS, Hershman EB, Hoellrich RG, Hosea TM, Johnson DC, Johnson TS, Jones MH, Kaeding CC, Kamath GV, Klootwyk TE, Levy BA, Ma CB, Maiers GP, Marx RG, Matava MJ, Mathien GM, McAllister DR, McCarty EC, McCormack RG, Miller BS, Nissen CW, O'Neill DF, Owens BD, Parker RD, Purnell ML, Ramappa AJ, Rauh MA, Rettig AC, Sekiya JK, Shea KG, Sherman OH, Slauterbeck JR, Smith MV, Spang JT, Svoboda SJ, Taft TN, Tenuta JJ, Tingstad EM, Vidal AF, Viskontas DG, White RA, Williams JS, Wolcott ML, Wolf BR, York JJ. Meniscal and Articular Cartilage Predictors of Clinical Outcome After Revision Anterior Cruciate Ligament Reconstruction. Am J Sports Med 2016;44(7):1671-9. Crossref

31. Anand BS, Feller JA, Richmond AK, Webster KE. Return-toSport Outcomes After Revision Anterior Cruciate Ligament Reconstruction Surgery. Am J Sports Med 2016;44(3):580-4. Crossref

32. Franceschi F, Papalia R, Del Buono A, Zampogna B, Balzani LD, Maffulli N, Denaro V. Two-stage procedure in anterior cruciate ligament revision surgery: a five-year follow-up prospective study. Int Orthop 2013;37(7):1369-74. Crossref

33. Mitchell JJ, Chahla J, Dean CS, Cinque M, Matheny LM, LaPrade RF. Outcomes After 1-Stage Versus 2-Stage Revision Anterior Cruciate Ligament Reconstruction. Am J Sports Med 2017;45(8):1790-8. Crossref

34. Carlisle JC, Parker RD, Matava MJ. Technical considerations in revision anterior cruciate ligament surgery. J Knee Surg 2007;20(4):312-22. Crossref

35. Grossman MG, ElAttrache NS, Shields CL, Glousman RE. Revision anterior cruciate ligament reconstruction: threeto nine-year follow-up. Arthroscopy 2005;21(4):418-23. Crossref

36. Noyes FR, Barber-Westin SD. A comparison of results in acute and chronic anterior cruciate ligament ruptures of arthroscopically assisted autogenous patellar tendon reconstruction. Am J Sports Med 1997;25(4):460-71. Crossref

37. Harilainen A, Sandelin J. Revision anterior cruciate ligament surgery. A review of the literature and results of our own revisions. Scand J Med Sci Sports 2001;11(3):163-9. Crossref 